\title{
Investigation of the Social Factors Affecting Social Well-being of the Employees Case Study: Department of Education, Ahvaz
}

\author{
Mahsa Rahdarzadeh \\ Department of social sciences, shoushtar Branch, Islamic Azad University \\ Shoushtar, Iran; mahsarahdarzadeh@gmail.com \\ Mahdi Adibisedeh \\ Department of social sciences, shoushtar Branch, Islamic Azad University \\ Shoushtar, Iran; m.adibi.sedeh@gmail.com; Corresponding Author
}

Doi:10.5901/mjss.2016.v7n3s2p194

\section{Abstract}

The present study is an attempt to investigate the social factors affecting public health of employees in the Ahvaz department of education. The required Data were collected through survey methods using self-report questionnaire distributed among a sample of 384 employees in the Ahvaz department of education who were selected through simple random sampling using Cochran formula. The hypotheses of the study were tested through Pearson correlation index, Spearman correlation index, and multivariate regression tests. The results showed that there is a significantly positive relationship between social factors (social support, life satisfaction), and social well-being.

Keywords: social well-being, social support, life satisfaction, department of education

\section{Introduction and Statement of Problem}

Healthy human is the pillar of development in any society. Progress and development can be achieved in the shadow of sustainable and holistic physical, mental and social well-being of the society, accordingly, human development has been one of the most important parameters of Development Studies since the 80 decade of the $20^{\text {th }}$ century. Health, public health is the base. These two are so interdependent that cannot be defined boundaries between them. Individual Health is the base of public health. These two factors are so interdependent that no boundaries can be drawn between them. The Individual health status in a society affects the health and emotions of others as well as social and economic indices of the society in a variety of ways. Therefore, securing the health of individuals in a society as an entity dependent on its members, is very critical and important.

Safety and health have been regarded as fundamental concepts in human life since the dawn of mankind for many centuries, and man has always mobilized all resources and forces to achieve them. However, in the discussions of this phenomenon, the physical and to some extent the mental aspects (only in recent years) are mainly placed at the center of attention, while the social aspect has received little attention. The World Health Organization (1948) drew the attention of all countries towards providing the society members with mental, physical and social well-being while emphasizing on the fact that none of the health aspects is superior to the other. Growth and development of a given society depends on the health of that society, and identification of the determinant factors in this regard for policy making and planning at micro and macro levels of society from the physical, psychological and social perspectives is essential for every country (Roqanchi, 1384: 15).

Social well-being is a sort of mental, social and individual health whose realization motivates citizens and gives them a happy spirit, finally leading to a refreshed and healthy society. In fact, healthy life is the product of social interactions between the individual choices on the one hand and the social and economic environment surrounding them on the other hand. According to Led Smith social well-being is assessment of the significantly positive and negative behaviors of individuals in relation to others and is regarded as one of the most basic health indicators for any society that will lead to effectiveness of individuals in society (Larson, 1993: 285). This is particularly true about our society as a developing society in transition stage. Because, on the one hand, the society we are living in is a society with a large young population, and this young population which is the main capital for development or country needs to pay attention 
to health, social well-being in particular, and interactions on social networks. On the other hand, a young individual who doesn't enjoy adequate psychological and social well-being can't deal with the challenges arising from the performance of social roles and adapt to the social norms. Thus, since social well-being is a concept that is manifested in the society and in relationships between people in social networks, and according to what was mentioned above, it can be said that social conditions in any society could play a major role in formation of that society. Therefore, in this study attempts are made to answer this question: What are the social factors affecting the department of education employees in the city of Ahvaz? The planners can draw on the results of this research to promote the social well-being of their society.

The importance and necessity of the study

In today's world it is very difficult to have a dynamic and developing society without any efficient system of health and social welfare. For many years, politicians and policymakers often regarded health and social welfare only as social factors. But considering the important impact of health and social welfare on the productivity of labor force and human capital in society as well as the relationship between economic growth and social welfare, health and social welfare are not merely a social factor anymore. In fact, addressing the issue of health and social welfare in line with expansion of social justice is considered an important goal for governments and a core factor in any socio-economic development program.

Good relationships with others, the quality of working life, learning life skills, leisure activities and the satisfaction with them, social security systems, the utilization of educational system, and civil rights are in the broad sense, the social well-being indicators which are perceived differently in all countries throughout the world. Investigation of the relationship between each of the above indicators and the social well-being of people in a society seems to be essential for different kinds of planning.

\section{Research Objectives}

The primary goal of this research is to investigate the social factors affecting social well-being of the education department employees in Ahvaz.

The secondary objectives

- Understanding the relationship between social support and social well-being of the education department employees in Ahvaz;

- Understanding the relationship between life satisfaction and social well-being of the education department employees in Ahvaz

\section{Review of Litrature}

- In a study entitled "the relationship of social well-being and its indicators with the quality of life among employees of the Melli Bank in Tehran" conducted by Latifi and Movahedi (1390), showed that there is a a positive relationship between social well-being and the quality of life. The results also showed that only two sub-scales (social cohesion and social prosperity) out of the 5 sub-scales of social well-being, have a significant positive relationship with the quality of life.

- Qaedi and Yaqubi (1386), conducted a study entitles" investigation of the relationship between perceived social support and welfare aspects among the male and female students of Tehran University and Allameh Tabatabai university. the Results showed that the aspects of perceived social support are better anticipators of life satisfaction and emotion balance in girls compared to boys, the results also showed that the psychological and social well-being of girls is mostly anticipated by social support from family while the psychological and social well-being of boys is mostly anticipated by social support from friends.

\section{Research Methodology}

This is a survey study in which data are collected through sampling and questionnaires. The statistical population included all the employees of education department in the city of Ahwaz in 1388 who are a total of 16378 individuals according to the Statistical Yearbook of the Khuzestan province (1391). of these 16378 people are. The Cochran's formula was used to determine the sample size (384)

Data collection in this study was conducted in the following way:

Formulation and collection of the literature on the subject of this study and investigation of the data related to that, was conducted through library study of the related books, articles and theses. Much of the data were collected through 
questionnaires. To this end, a structured questionnaire which is provided in the next section of the study, was designed and distributed among the sample members. This method allows us to obtain uniform information about the population, and to compare and observe the right variables.

A copy of the questionnaire was given to the supervisor and the advisor so that they can determine the face validity of the questionnaire and provide their suggestions and opinions on that. After extraction of the questionnaire scores and insertion of them to a computer, Cronbach's alpha was used to estimate the reliability of the questionnaire and the following coefficients were obtained for each scale. Since all the coefficients obtained for variables exceeded 0/70 it can be concluded that the research instrument is reliable and trustworthy. Both descriptive and inferential statistics were used to analyze the data and the data processing was performed by the spss 16 software

\section{Hypotheses Testing}

First hypothesis: there is a significant relationship between the social support and social well-being of the education department's employees in the city of Ahvaz. The obtained correlation coefficient and significance level were equal to 0/097 and 0.000 respectively. The results of this test showed, with high significance (sig $=0 / 000<01 / 0)$, that there is a significant positive relationship between social support and social well-being. In other words, with any increase in social support, the social well-being level would increase accordingly. The result of this study is consistent with the results of the research conducted by Qaedi and Movahedi (1390). These results are shown in Table 1.

Table 1. The results of Pearson correlation coefficient for testing the correlation between social support and social wellbeing

\begin{tabular}{|c|c|l|l|}
\hline Social well-being & Social support & & Category \\
\hline $0 / 097$ & 1 & Pearson coefficient & \multirow{2}{*}{ Social support } \\
\hline $0 / 00$ & 0 & Sig. level & \\
\hline 384 & 384 & number & \multirow{3}{*}{ Social well-being } \\
\hline 1 & $0 / 097$ & Pearson coefficient & \\
\hline 0 & $0 / 00$ & Sig. level & \\
\hline \hline 384 & 384 & number & \\
\hline \hline
\end{tabular}

The second hypothesis: there is a significant relationship between life satisfaction and social well-being of the education department's employees in the city of Ahvaz. The obtained correlation coefficient and significance level were equal to $96 / 006$ and 0.000 respectively. The results of this test showed, with high significance (sig $=0 / 000<01 / 0)$, that there is a significant positive relationship between life satisfaction and social well-being. In other words, with any increase in life satisfaction, the social well-being level would increase accordingly. The result of this study is consistent with the results of the research conducted by Pourroodsary, Peyravi and Abedian (1384). These results are shown in Table 2

Table 1. The results of Pearson correlation coefficient for the testing the correlation between life satisfaction and social well-being

\begin{tabular}{|c|c|c|c|}
\hline Social well-being & Life satisfaction & & \multirow{2}{*}{ category } \\
\cline { 1 - 3 } $\mathbf{9 6 / 0 0 6}$ & 1 & Pearson coefficient & \multirow{2}{*}{ Social support } \\
\cline { 1 - 3 } $\mathbf{0 / 0 0}$ & 0 & Sig. level & \\
\hline 384 & 384 & number & \\
\hline 1 & $96 / 006$ & Pearson coefficient & \multirow{2}{*}{ Social well-being } \\
\hline 0 & $0 / 00$ & Sig. level & \\
\hline \hline 384 & 384 & number & \\
\hline
\end{tabular}

\section{Conclusion}

The results showed that there is a significant positive relationship between social support and social well-being. In other words, with any increase in social support, the social well-being increases accordingly. in interpretation of the results, it can be stated that social support would relieve the bond requirements, social support can meet the contact and 
socialization needs and obviation of devastating effects of isolation, loneliness and depression accordingly. With support, people can achieve a sense of belonging and this would satisfy the bond requirement needs. Social support together with functions such as attention, compassion, understanding, intimacy and effectiveness can increase the sense of belonging. Social support creates mutual obligations and provides a state in which a person feels love, care, self-esteem and dearness, and these are positively correlated with the social well-being outcomes.

The results also showed that there is positive and significant relationship between life satisfaction and social wellbeing. In other words, with any increase in life satisfaction, the social well-being would also increase accordingly. Life satisfaction could promote the social well-being of people. The sense of satisfaction is the factor that help people achieve their ideals and master the personal and social life problems. In fact, life satisfaction and concepts associated with that provide the ground for people to feel more satisfied with themselves and the world they live in, and these cases are naturally correlated with social well-being outcomes.

\section{Suggestions for Further Studies}

Given the importance of social well-being in the society, especially among the employees of the education departments, attempts must be made to find ways to increase it. Therefore, according to theoretical framework of this study and the obtained results, the following suggestions are provided for further studies:

- taking social, economic, and political measures to boost life satisfaction and enhance the quality of the employees life.

- Formulation of social and psychological strategies for the employees, in order to provide them with mental Comfort and social well-being.

- Formulation of economic and social policies by the governmental and public bodies in order to satisfy the needs and concerns of the employees.

\section{References}

Hosseini, F. (1387). Investigation of Social well-being status and influencing factors among the students of Allameh Tabatabai University , Faculty of Social Sciences. Master's dissertation, Faculty of Social Sciences, Allameh Tabatabai University.

Aram, S, A, A. (1388). Investigation of the social well-being with an emphasis on community-oriented policing approach, Journal of social regulation, the first year (1).

Sotoodeh, H. (1386). Social pathology, Tehran: Avaye noor, the eighteenth edition.

Tabardarzi, A. (1386). Investigation of The relationship between social-well-being and socio-demographic variables among the students at the University of Social Welfare and Rehabilitation Sciences, Tehran, MA thesis on Sociology, University of Allameh Tabatabai.

Latifi, Gh. R and Movahedi, A. (1390). Investigation of The social well-being and its indices' relationship with the quality of life among the National Bank of Tehran staff, MA. Thesis on sociology, Tehran University.

Manzari Tavakoli, A. and Araghipour, N. (1389). The relationship between religiosity and happiness among female students of Islamic Azad University, Kerman academic year 1389-1388, Journal of Educational Psychology, Vol. 6, No. 19, pp. 45-19.

Naderi, F; Asgari, P. Adaryani, M. (1389). The relationship between Spiritual intelligence and emotional intelligence and life satisfaction among the elderly in Ahwaz. New findings in psychology, fourth edition, №. 2, pp. 136-127.

Hershenson, d. And Power, P.W., (1998). Mental health counseling: Theory and Practice, (translated by Mohammad Taqi Maneshi Toosi), Mashhad. Astan Quds Razavi. 